\title{
Tunable Conjugated Polymers for Bacterial
}

\section{Differentiation}

\section{Mohsen Golabi, Anthony P F Turner, Edwin W H Jager*}

Biosensors and Bioelectronics Centre, Dept. of Physics, Chemistry and Biology (IFM), Linköping Unive

rsity, 581 83, Linköping, Sweden

Keywords: Conducting polymer; Polypyrrole; in-line bacterial detection; Rapid methods;

Bacterial adhesion; pattern recognition; Principal Component Analysis (PCA) 


\section{Abstract}

A novel rapid method for bacterial differentiation is explored based on the specific adhesion pattern of bacterial strains to tunable polymer surfaces. These preliminary investigations lay the foundation for the development of an electronically tunable array of sensors that will provide patterns of information to feed into computational recognition algorithms to enable swift diffentiation of bacterial species. Different types of counter ions were used to electrochemically fabricate dissimilar polypyrrole (PPy) films with diverse physicochemical properties such as hydrophobicity, thickness and roughness. These were then modulated into three different oxidation states in each case. The dissimilar sets of conducting polymers were exposed to a number of different bacterial strains. Generally, the number of cells of a particular bacterial strain that adhered varied when exposed to dissimilar polymer surfaces, due to the effects of the surface properties of the polymer on bacterial attachment. Similarly, the number of cells that adhered varied with different bacterial strains exposed to the same surface, reflecting the different surface properties of the bacteria. Five different bacterial strains, Deinococcus proteolyticus, Serratia marcescens, Pseudomonas fluorescens, Alcaligenes faecalis and Staphylococcus epidermidis, were seeded onto various PPy surfaces. By analysis of the fluorescent microscope images, the number of bacterial cells adhered to each surface were evaluated. Principal Component Analysis showed that all had their own specific adhesion pattern with respect to the set of applied PPy areas. Hence, these strains could be discriminated by this simple, label-free method. In summary, this provides a proofof-concept for using specific adhesion properties of bacterial strains in conjunction with tunable polymer arrays and pattern recognition as a method for rapid bacterial identification in situ.

\section{Introduction}


Rapid bacterial detection is required in many fields including clinical diagnostics, food and water safety, biosecurity and bioprocess control [1]. Although standard bacterial identification methods based on culturing are powerful, accurate and dependable, they are also cumbersome, tedious and take at least two days to deliver a result after sampling. These methods also require specific media, laboratories and trained staff [2-4]. Despite the recent introduction of a wide range of commercially available bacterial detection methods, including molecular biology-based techniques such as polymerase chain reaction (PCR), restriction fragment length polymorphism (RFLP), DNA microarray assays, and immunological techniques such as enzyme-linked immunosorbent assay (ELISA) and flow cytometry, most of these methods remain expensive, need special pre-treatment and require expert operators, which restricts their effectiveness as rapid and easy-to-use methods. The use of labile components such as enzymes and antibodies also severely limits their potential application on-line or in-line for process control.

Conjugated or conducting polymers, such as polypyrrole, have been used in biomedical and cell biology research because they provide both electronic and ionic-charge carriers and thus make for a good interface to electronically control, stimulate or sense biological species. They have been used for bio-sensing [5-7], as electrodes for stimulation or recording [8,9], for controlling cell adhesion, proliferation [10-12] and stem-cell differentiation [13], for controlled drug release [14, 15] and even to mechanically stimulate cells [16]. They can be fabricated electrochemically using various counter ions [17-19] and modified with a variety of biomolecules $[5,6,20]$. Surface properties of these very well studied polymers can be effectively controlled and reproduced by controlling the polymerisation conditions as well as by using appropriate counter ions. The use of various types of dopants in combination with different polymerisation conditions influences 
polymer surface properties like thickness, roughness, conductivity and hydrophobicity [17, 21-23] and has been shown to influence cell viability $[18,19,24]$.

Bacteria grow in two states, planktonic form and attached to surfaces as biofilms. Cell gene expression and its phenotypes in the same microorganism differ in these two situations [25, 26]. Changing state from planktonic to biofilm formation starts by adhesion of the bacterial cell to the surface [27]. There are two main factors affecting bacterial attachment to a surface: cellular properties and environmental factors [28, 29]. Many surface features can affect bacterial adhesion, including roughness, hydrophobicity and the natural properties of the surface materials [30-32]. Interaction of bacterial cells with various surfaces has been studied for many years, especially with respect to biofouling. For instance, coating materials which have the ability to decrease bacterial attachment to the surface have many applications in medical implants, food processing, agriculture and ship design $[33,34]$. Many reports describe that seeding different bacterial strains onto similar surfaces results in different amounts of adherence $[35,36]$. This difference could be related to the existence of different physicochemical characteristics between species and strains [37]. Surface proteins and extracellular organs such as pili, fimbria, flagella and curli help bacteria to attach to the surfaces [38]. Different ratios and biochemical composition of these cell wall appendages cause variation in adhesion properties between different bacterial species and even different strains of the same species [39].

Despite this wealth of literature, there are no previous reports of using adhesion properties in a systematic way to produce a programmable array for rapid, label-free detection and identification of bacteria. We propose that identifying microorganisms based on their specific adhesive properties to different or modulated surfaces, generating a species or strain specific adhesion pattern, could lead to a fast diagnostic and novel bacterial detection tool. 
One new method for bacterial discrimination which has been extensively reported during recent decades is the electronic nose. E-noses are based on using a sensing array of individual gas sensors to identify specific recognition patterns related to particular mixtures or microbial populations [4043]. These studies demonstrate the potential of using a specific pattern recognition array in order to rapidly characterise an unknown sample. Here, we evaluate a novel extension of this theme by using a set of polymers to discriminate bacteria based on their specific adhesion patterns. We have illustrated this principle by preparing four dissimilar-doped PPy films, each in three states, oxidised, reduced and as fabricated, with different surface properties, to discriminate five bacterial strains belonging to different classes or orders. We envisage an array that, in combination with an appropriate transducer and pattern-recognition software, will detect the strain specific adhesion patterns, providing a convenient and inexpensive biosensing device able to rapidly and specifically detect or monitor changes in microbial populations in applications such as food fermentation, where the correct balance of species must be maintained. Furthermore, since the surface properties of PPy films can be electrochemically modulated in real time, the opportunity exists to add a further dynamic to the measurement to enhance differentiation and expand the range by using a smart sensing array. 


\section{Experimental Section}

2.1. Polypyrrole synthesis: Pyrrole monomer (Sigma-Aldrich, St. Louis, USA) was distilled and stored at $-20^{\circ} \mathrm{C}$ prior to usage. Four dopants were used to in situ electrochemically synthesise four types of polypyrrole film on gold coated silicon chips. Sodium p-toluene-sulfonate (ToS) was obtained from Acros Organics (New Jersey, USA). Dodecylbenzene sodium sulfonate (DBS) was purchased from TCI (EUROPE N.V, Belgium). Poly (sodium 4-styrene-sulfonate) (PSS) was purchased from Sigma-Aldrich and sodium chloride was purchased from Merck (Darmstadt, Germany). The four PPy films were electrochemically synthesised and in situ deposited on the gold coated silicon chips with $1 \mathrm{~cm}^{2}(10 \mathrm{~mm}$ by $10 \mathrm{~mm})$ accessible surface area using a constant potential of $650 \mathrm{mV}$ and a fixed charge of $100 \mathrm{~m} \mathrm{C}$ in an electrolyte solution containing $0.1 \mathrm{M}$ pyrrole monomers and 0.1 $\mathrm{M}$ of the respective dopant in de-ionised water (Milli Q, 18.2 M $\Omega$ ). The solution was deoxygenated by using an oxygen-free nitrogen gas flow for 5 min before the polymer fabrication. To reduce variation and increase reproducibility, the gold working electrodes were cleaned using a RCA1 solution (5:1:1 mixture of D.I water, ammonia $25 \%$ and hydrogen peroxide $28 \%$, respectively, for $10 \mathrm{~min}$ at $85^{\circ} \mathrm{C}$ ) before the polymerisation process and kept in de-ionised water prior to use. The constant potential was applied using a Compactstat.e (Ivium Technology, The Netherlands) potentiostat. A three-electrode configuration was used where the gold coated chip was employed as the working electrode, a platinum mesh $(40 \mathrm{~mm}$ by $50 \mathrm{~mm})$ as the counter electrode and an $\mathrm{Ag} / \mathrm{AgCl}$ electrode was used as the reference electrode. The measured deposition current transients for the four different PPy electrosynthesis are shown in Figure S1.

2.2 Electrochemical oxidation or reduction: In order to increase the number of dissimilar surfaces and add another, dynamic level of tuneable surface properties the PPy films were electrochemically modulated in real time. The redox state, and thus surface properties, of the four 
PPy surfaces was altered by either reducing or oxidising the PPy using a fixed potential of $-0.9 \mathrm{~V}$ or $+0.3 \mathrm{~V}$ for $300 \mathrm{~s}$, respectively. The same three-electrode system as used for the electrosynthesis was used except that the electrolyte was a solution of $0.1 \mathrm{M}$ of the dopant in de-ionised water. The measured current transients of the reduction and oxidation of the four different PPy surfaces are shown in Figure S2A and S2B, respectively.

2.3 Polymer surface characterisation: One drop $(10 \mu 1)$ of fresh Milli Q water $(18.2 \mathrm{M} \Omega)$ water was placed on the polymer surface and five images were recorded using a CAM200 Optical Contact Angle Meter (KSV Instruments, Finland). The average of the contact angle, computed by the accompanying software, was recorded as the measured contact angle. Surface thickness and roughness were determined using a Dektak 6M Profilometer (Veeco Instruments Inc., NY, USA). The reported data are average of three independent experiments. The Scanning Electron Microscopy (SEM) images were taken using a Leo 1550 Gemini SEM operating at $4.0 \mathrm{keV}$.

2.4 Bacterial Adhesion Tests: The five bacterial strains used in this study were Deinococcus proteolyticus, Serratia marcescens, Pseudomonas fluorescens, Alcaligenes faecalis and Staphylococcus epidermidis. All bacterial strains were acquired from the Culture Collection, University of Goteborg, Sweden except S.epidermidis which was obtained from Linköping University Hospital. Bacterial strains were grown in Tryptic Soy Broth (TSB), at $37^{\circ} \mathrm{C}$ and 170 rpm. The bacterial cells were cultured overnight (18hrs) and then harvested by centrifugation ( 5 min at $3756 \mathrm{~g}$ ). Supernatant was discarded and the pellet was re-suspended in sterile phosphate buffered saline (PBS) solution $(\mathrm{pH}$ 7.4). This procedure was repeated three times to remove organic and inorganic impurities. After the last centrifugation, the concentration of the bacterial cell was adjusted to $10^{8} \mathrm{cfu} / \mathrm{ml}$ by measuring the adsorption at $600 \mathrm{~nm}$ using a spectrophotometer (Shimadzu UV-1601 PC, Japan). The optical density equal to a concentration of $10^{8} \mathrm{cfu} / \mathrm{ml}$ for 
each bacterial strain had already been determined by the standard plate count method. Polymer samples were placed in each well of a 6-well microtitre-plate and $7.5 \mathrm{~mL}$ bacterial cell suspension was added to each well and incubated at $70 \mathrm{rpm}$ for 60 minutes at $37^{\circ} \mathrm{C}$. The samples were then gently rinsed three times with PBS to remove non- or weakly adhered cells. To quantitatively evaluate the number of adhered bacteria to the PPy surface, bacteria were stained by ethidium bromide $(0.05 \%, 45 \mathrm{~min})$. Images were taken at ten random positions on the surface of each sample using fluorescent microscope, corresponding to a total area of $1.25 \times 10^{5} \mu \mathrm{m}^{2}$. The images were analysed with ImageJ software (free download at http://imagej.nih.gov/ij/index.html) to count the number of bacterial cells on each of the images. The adhesion levels were given as number of cell $/ \mathrm{cm}^{2}$, averaged from these ten images. The final reproducibility was assessed by repeating the measurements on three independent samples $[26,30,65]$.

2.5 Principal component analysis: Principal component analysis was performed using the software SIRIUS 6.5 from Pattern Recognition Software, Norway.

\section{Results}

Figure S3 shows optical photographs and SEM images at various magnifications of the twelve fabricated samples. The higher magnification SEM images show the typical nodular cauliflower like structure of PPy. Figure 1 shows the thickness, roughness and wettability (water contact angle) parameters of the twelve polymer samples, that is, the PPy surfaces with the four different dopants and at three different redox states (as fabricated, oxidised and reduced). As shown in Figure 1a, PPS-doped polymer had the most hydrophilic surface. DBS- and ToS-doped fabricated polymers were in similar range of hydrophobicity. Altering the redox state had a significant effect on the wettability properties in DBS- and PSS- doped polymers. Variation in the wettability of different 
redox states of ToS and $\mathrm{Cl}$ doped polymers was also observed, but the differences were not as large as for DBS or PSS doped polymers. Both thickness and roughness were measured using a profilometer. The difference in thickness between the fabricated samples was clear; only (Tos) and (PSS)-doped polymers were in a similar range. Applying potential in order to change the redox state of the polymers had affected the polymer thickness. The PPy surfaces are relatively flat as evidenced by the SEM images (Figure S3B) and the roughness values of all surfaces that were relatively low, < $100 \mathrm{~nm}$. However, the as-fabricated states of ToS- and PSS-doped polymers were relatively rougher than the DBS- and Cl-doped polymers. Here again changing the redox state had clearly affected the roughness. However, the nature of this change was not similar in these sets of polymers. For example, although the oxidised state of PSS doped polymers was smoother than the as-fabricated ones, in the Cl-doped polymers the opposite was seen. There was no significant relationship between thickness and roughness to indicate that the type of dopant had more effect on polypyrrole roughness properties rather than on the thickness of the polymer.

In order to prove the principle of differentiation based on controllable polymer surface properties, five bacterial strains, D.proteolyticus, S.marcescens, P.fluorescens, A.faecalis and S.epidermidis, belonging to four different bacterial classes. From the class of Gamma Proteobacteria, we even chose bacteria ( $P$. fluorescens and $S$. marcescens) from two different orders. The bacteria were seeded onto the different surfaces. We chose three Gram negative and two Gram positive bacteria, in order to investigate whether having similar surface construction gives bacteria similar adhesion tendencies. In addition, bacteria were selected from different classes to check the possibility of phylogenic similarity with respect to adhesion to a particular polymer surface. To quantify the behaviour of the bacteria seeded on to these surfaces, the numbers of adhered bacterial cells on each sample were determined as described earlier. Figure $2 \mathrm{~A}$ shows the number of bacteria 
attached to the four types of polypyrrole, which were polymerised under the same conditions, but with different dopants and in their as-fabricated, non-switched state. Figure $2 \mathrm{~B}$ quantitatively shows the effect of different polymer surfaces on bacterial adhesion. As can be seen, the bacteria show a different adhesion pattern to the various surfaces. Figure 3 illustrates the effect of the redox state on bacterial adhesion. It shows that changing the redox state adds another level of differentiation. For instance, the as-fabricated PSS-doped PPy surface could not statistically differentiate between A.faecalis and S.marcescens, but when the PPy is reduced, the difference in adhesion is significant, likewise for the example of ToS-doped PPy. Figure 4 reveals the adhesion pattern of bacteria to all of the twelve arrays of the polymer films together with the Standard Deviation for each test. In order to get an overview and to search for structure in this vast amount of data, multivariate data analysis has proved to be a valuable tool. Principal component analysis (PCA) is a statistical procedure that calculates a vector which describes the direction of the largest variance in the experimental data, that is the direction that describes the largest differences between observations. This vector is called the first principal component. The second principal component is orthogonal to and thus independent of the first principal component.

The directions of the principal components in relation to the original variables or sensor responses are defined as the loading vectors and the score vectors describe the directions of the principal components in relation to the observations or experiments. Thus, corresponding to the loading vectors a loading plot can be made, showing the relationships between the original variables and how much they influence the system. A corresponding score plot shows the relation between the observations or experiments, and groupings of observations in the score plot can be used for classifications [44]. 
For the experiments described in this study, the score plot (Figure 5A) represents the correlation between the experiments of the various bacteria, i.e. the data of Figure 4, and the loading plot (Figure 5B) the correlation between the observations, that is the responses from the various PPy surfaces. The score plot thus shows how well the bacteria can be classified and since they cluster well, they are well classified. S.epidermidis, a Gram positive organism, exhibited a distinctly different pattern compared to the Gram negative organisms. However, D.proteolyticus, which is an atypical Gram positive organism behaved more similarly to Gram negative bacteria than S.epidermidis. Gram negative bacteria, used in this study, are not so closely clustered in the PCA plot, but they showed good repeatability. In the loading plot, the importance of each particular surface can be estimated. The further a point is positioned from the origin, the more important this surface is in differentiating the bacteria strains. For the particular set of bacteria used in this study it shows that DBS-doped polymers are important differentiators, while on the other hand reduced ToS- and oxidised Cl-polymers are least important. It is also interesting to see, for instance, that there is little differentiation capacity between reduced and oxidised PSS, and between as fabricated ToS and as-fabricated PSS. In summary, it was clear that the five bacterial strains used showed significantly different adhesion patterns with this set of polymer surfaces and this provides an important proof-of-principle for the proposed methodology.

\section{Discussion}

Bacterial adhesion to a surface is a complex process which starts by interaction of the cell surface structural macromolecules and the interface [45]. Many factors affect bacterial adhesion to a surface, including the properties of the surface material, environmental conditions and also the bacterial cell surface properties, and this makes it a complex and multifactorial phenomenon $[42$, 46-50]. Bacterial cell attachment to a surface is generally described by two stages; initial 
attachment, which is rapid and reversible and involves physicochemical interactions between bacterial cell surfaces and the material surfaces, and non-reversible attachment, which involves specific and non-specific interactions between proteins on the bacterial surface structures and binding molecules on the material surface, as well as physicochemical interactions $[51,52]$. Changing the parameters which mainly influence bacterial attachment, such as charge, hydrophobicity and roughness [53,54], can increase or decrease bacterial attachment and have found various specific applications (for example biomedical implants should inhibit bacterial attachment while, in some cases in biotechnology, the attachment of bacteria to a surface is desirable). The extensive literature in these areas reveals that changing surface parameters has different effects depending on the kind of bacteria [49]. One of the surface parameters which has a drastic effect on bacterial adhesion is hydrophobicity of both the surface of cells and materials [55]. It has been observed that bacterial cells have a greater tendency to attach to hydrophobic surfaces than hydrophilic surfaces. However, in some cases the surface tension of the suspending medium and the bacteria can change this expectation $[54,56]$. So, the relationship between the number of adhering microorganisms in relation to the surface hydrophobicity still seems to be controversial $[57,58]$.

Water contact angle is a parameter which indicates the hydrophobicity of surface materials. Figure 1.a demonstrates the hydrophobicity of the twelve polypyrrole samples. PSS-doped polymers have hydrophilic surfaces property while $\mathrm{ToS}$ and $\mathrm{Cl}$ have less hydrophilic properties. These data are in agreement with other reports which indicate the role of the dopant in the wettability of polypyrrole [21]. The redox state altered the hydrophobicity of the polymer surfaces, but the impact of this effect varied due to the type of dopant. DBS-doped polymer showed a drastic change in hydrophobicity in the different redox states [59]. Comparing Figure 1.a and 2B shows some 
correlation between water contact angle and adhesion in some cases. Because changing dopant or redox state also changes other physicochemical properties which affect bacterial adhesion, it is not easy to resolve the impact of the individual parameters on bacterial adhesion. For our purposes, the wettability of the polymer surfaces could be controlled by using an appropriate dopant and the redox state conditions $[17,22,23,60]$. Roughness is described as the typical height variation on the surface. Many researches have tried to describe the relationship between roughness and bacterial adhesion. Although, there is still not a general agreement on the subject of the minimum level of roughness which affects the bacterial adhesion, a strong relationship between bacterial adhesion and surface roughness has been highlighted [57,61]. Almaguer et al., surveyed the impact of surface roughness and surface chemistry on the adhesion of oral bacteria and they reported that depending the type of bacteria, each factor could have more effect on bacterial colonisation [46]. Not only roughness, but also the topography of the surface can affect bacterial adhesion [62, 63]. Hsu et al., found that bacterial cells exhibit different behaviour depending on the topographical details of the surface to which they attached [30]. So, changing one surface parameter did not deliver a predictable result and adhesion should be considered as a complex response related to all ambient conditions and bacterial behaviour. Figure 1.b and c show the roughness and the thickness of the set of polymer used in this study; there was no significant relationship between thickness and roughness. Since the mass amount of electro-polymerised polypyrrole is directly proportional to the amount of charge passed during synthesis, all samples were equal with respect to the amount of polypyrrole. On the other hand, the thickness of polymer is related to the charge passed, surface area of the working electrode and the density of final product [21]. Because in this case the charge and surface area were fixed in all samples, the difference in thickness is related to the contribution of each dopant in the final mass product and/or 
the different density of each polymer type. There is also no clear relation between roughness and thickness even among the different redox state of the same doped polymer. From this it can be concluded that the different redox states of the same doped polymers also have different physicochemical properties, which conveniently fits with our proposed method. The type of dopant and redox state has considerable impact on the thickness, roughness and hydrophobicity of PPy, which in turn affects the bacterial attachment and enables us to fabricate a set of surfaces with, varies surface properties. In our experiments, we observed that the polymer surface properties will change not only with dopant type and redox state, but also with polymerisation technique and even polymerisation parameters such as charge and voltage. All these affecting factors provide the ability to make many different tunable conjugated polymer surfaces as potential constituents for a high density array.

Many scientific articles report that related bacterial strains show different adhesion properties on a similar surface and under the same environmental conditions, due to their different surface proteins and/or appendices $[64,65]$. Since bacterial appendices and cellular surface properties are genetically determined and are species or even strain specific, the ability or tendency of bacterial cells to attach to surfaces is species or strain specific and can, in principle, be used as a new method for bacterial discrimination, detection and identification. The current study demonstrates such inherent behaviour of five bacterial strains exposed to dissimilar surfaces and illustrates the potential for bacterial discrimination using a variety of polymers. This principle could be expanded for the fabrication of larger micro-fabricated arrays to provide a new kind of robust, label-free sensor for bacterial differentiation. As a proof-of-concept of our new method, five different bacteria, both Gram positive and Gram negative, were used. 
In classical microbiology bacterial strains differentiate by their cell wall structures into Gram positive and Gram negative. These two groups have totally different chemical properties on their bacterial surfaces. The Gram positive bacterial surface is composed of peptidoglycan and teichoic acids with high oxygen: carbon ratio, which causes the surface to be more hydrophilic, whereas a Gram-negative bacterium is composed of an outer membrane with lipids and lipopolysaccharides with high ratio of nitrogen/carbon due to the presence of proteins, which cause the surface to be more hydrophobic [56]. Figure 2A qualitatively demonstrates the different response of these bacterial strains exposed to a set of different polymer surfaces. The fact that different amounts of these bacteria adhered to the same surfaces under identical condition indicates the impact of cell surface properties on bacterial adhesion. Figure 3 illustrates the response to a dynamic redox state and how this increases the ability of a particular type of surface to discriminate bacterial strains. Although, A.faecalis and S.marcescens showed the same adhesion tendency to the both the asfabricated PSS and ToS doped PPy, the amount of adhered bacteria on the surfaces changed following the induced change of the polymer's redox state.

To quantitatively illustrate the concept, as shown in Figure 2A, bacterial cell count using software analysis of the images, Figure 2B, 3, and 4, and the subsequent PCA plot in Figure 5, reveal the difference between bacterial adhesion properties. As has been discussed, the adhesion of bacterial cells to a surface is a complex process which is affected by many parameters. It is hard to say whether thickness, roughness, hydrophobicity or type of dopant has the main effect on the variation of the number of a bacterial strains attachment to different surfaces. It could be assumed that a combination of all these variables determined the amount of adhesion for each sample. For our purposes, however, a precise understanding of the mechanism is unnecessary as long as a suitable array for differentiation can be fabricated that creates a different adhesion pattern for each strain. 
Biochemical fingerprints of whole cells have provided the basis for several new bacterial detection tools including mass spectrometry (MS), vibrational spectroscopy (Raman and infrared), electronic noses and light scattering analyses [58]. Pattern recognition techniques utilising the electronic nose (e-nose) in particular, have been proposed for use in many fields including microbial detection for medicine and food quality control [43, 66-68]. Here, we introduce a new strategy for bacterial discrimination based on bacterial adhesion properties which builds on this established body or work, but offers a new direction for research and application. E-noses are based on bacterial volatile organic compounds, which do not vary much within a group of related bacteria, for example among bacterial species belonging to the same genus of bacteria. However, the distinct differences in adhesion properties of different bacterial species or even strains have been widely reported $[45,64,65]$. In summary, we have shown that different bacteria show dissimilar and distinct adhesion patterns and that these can be used for bacteria discrimination. From a phylogeny view point, D.proteolyticus and $P$. fluorescens are widely separated, but in this study they showed closely similar adhesion patterns. Hence, like many new methods, correlation with conventional taxonomy may not be present and a more pragmatic way of utilising the approach will need to be adopted.

\section{Conclusion}

This work provides a proof-of-concept of using a range of simple, tunable polymers that provide different adhesive properties as a new label-free method for bacterial differentiation. The results demonstrate that the tendency of different bacterial strains to adhere to a similar surface is different. Although, some bacterial strains might display a similar range of attachment to one surface, the overall pattern of the attachment is distinct when a range of surfaces is used. These characteristic bacterial adhesion patterns provide a simple and robust means to discriminate 


\section{Supplementary Information}

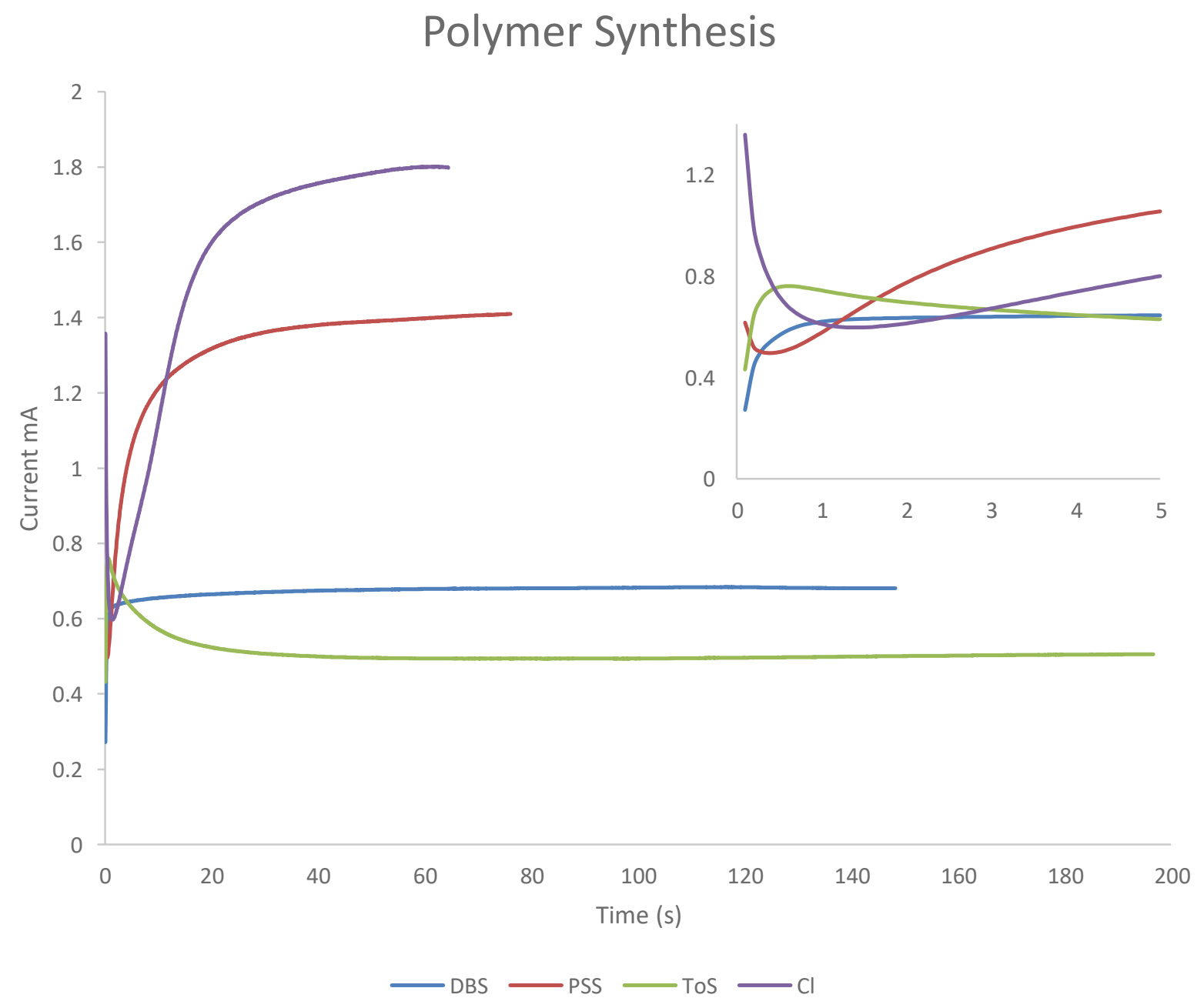

Figure S1. Transient curve of the electrochemical synthesis PPy. V applied $=650 \mathrm{mV}$. Inset: a magnification of the first $5 \mathrm{~s}$. 


\section{Polymer Redoction}

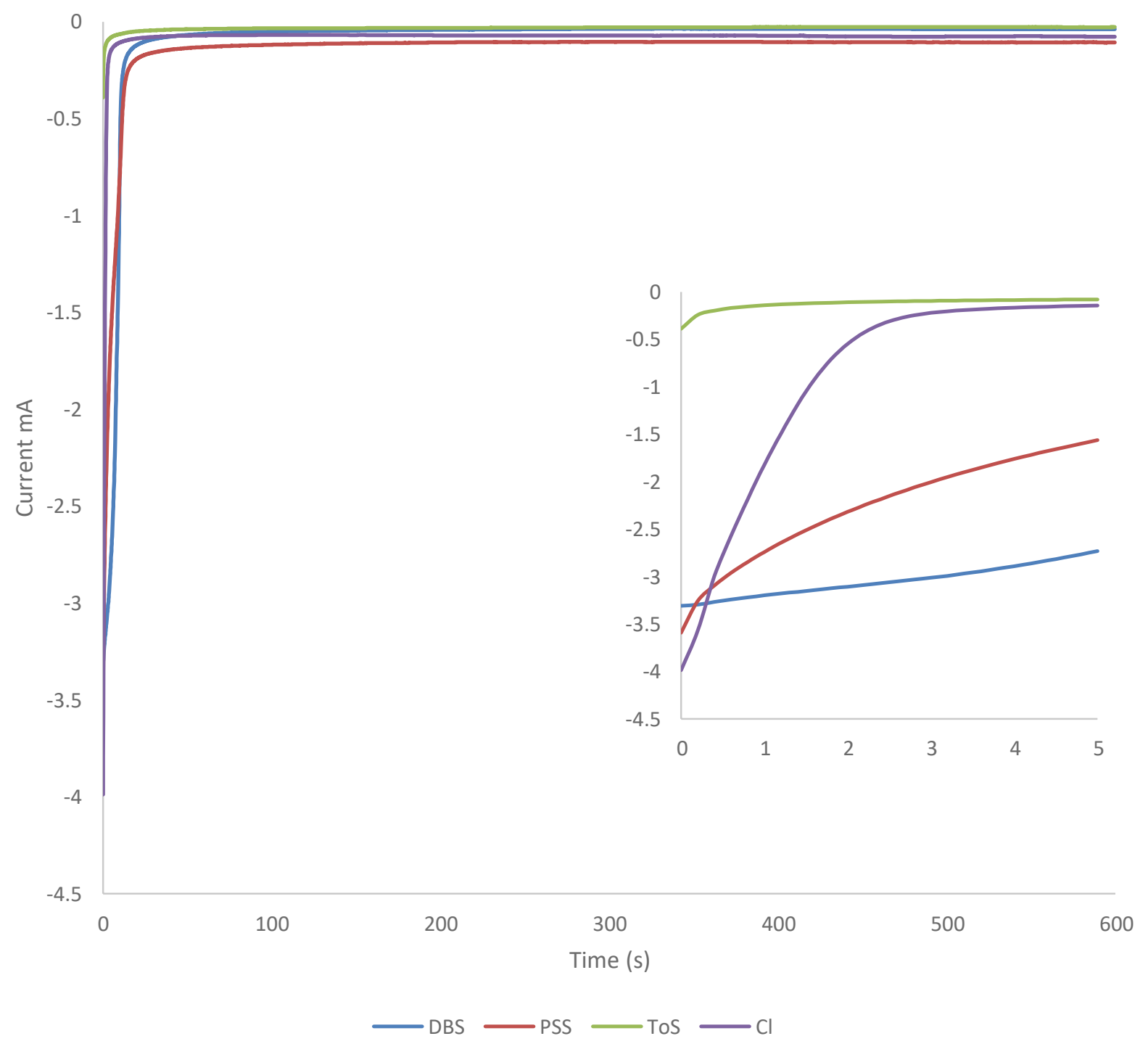

Fig S2 A. Transient curves of the Reduction of the different PPys used. Inset: a magnification of the first $5 \mathrm{~s}$. 


\section{Polymer Oxidation}

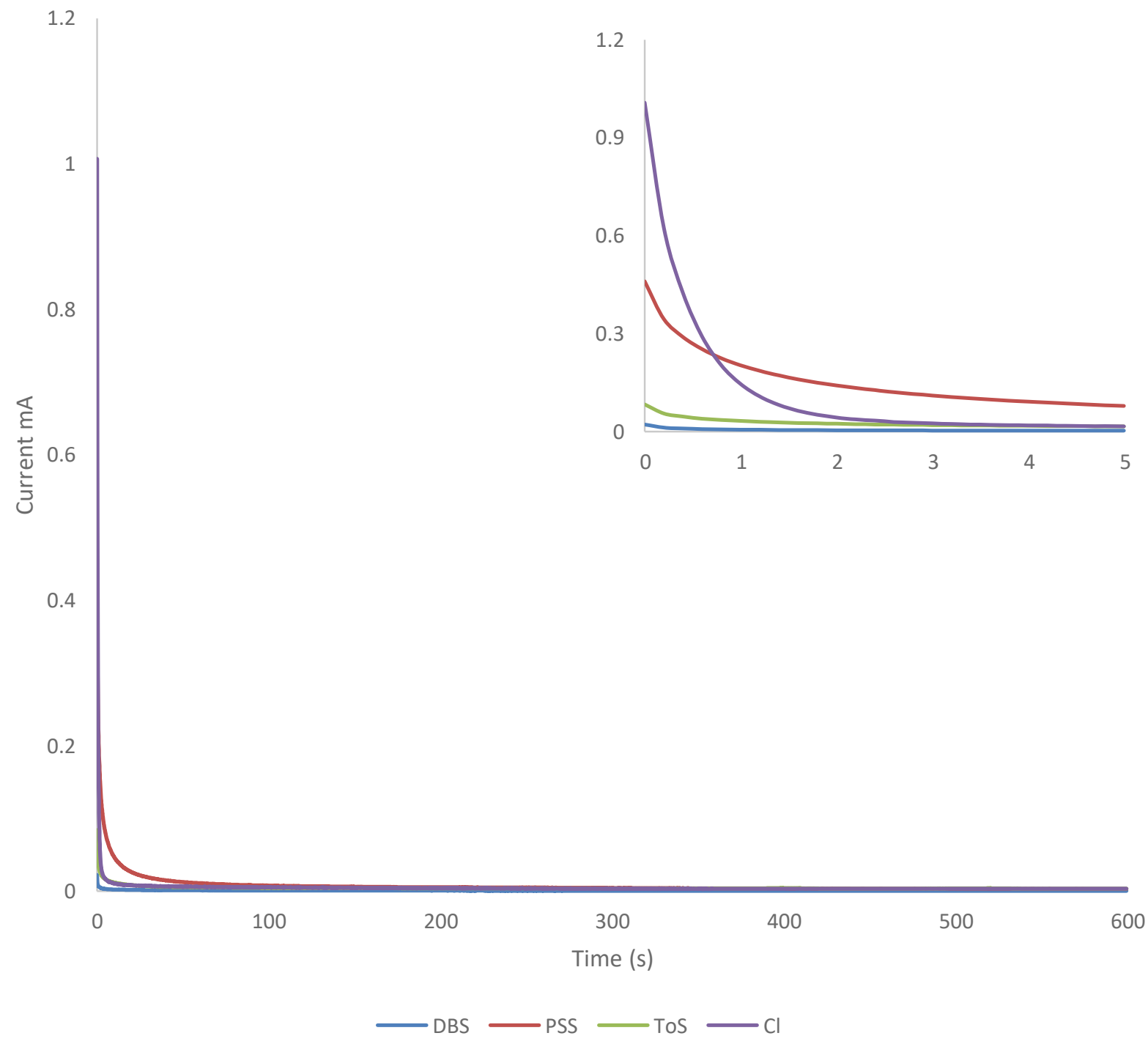

Fig S2B. Transient curves of the Oxidation of the different PPys used. Inset: a magnification of the first $5 \mathrm{~s}$. 
Fabricated
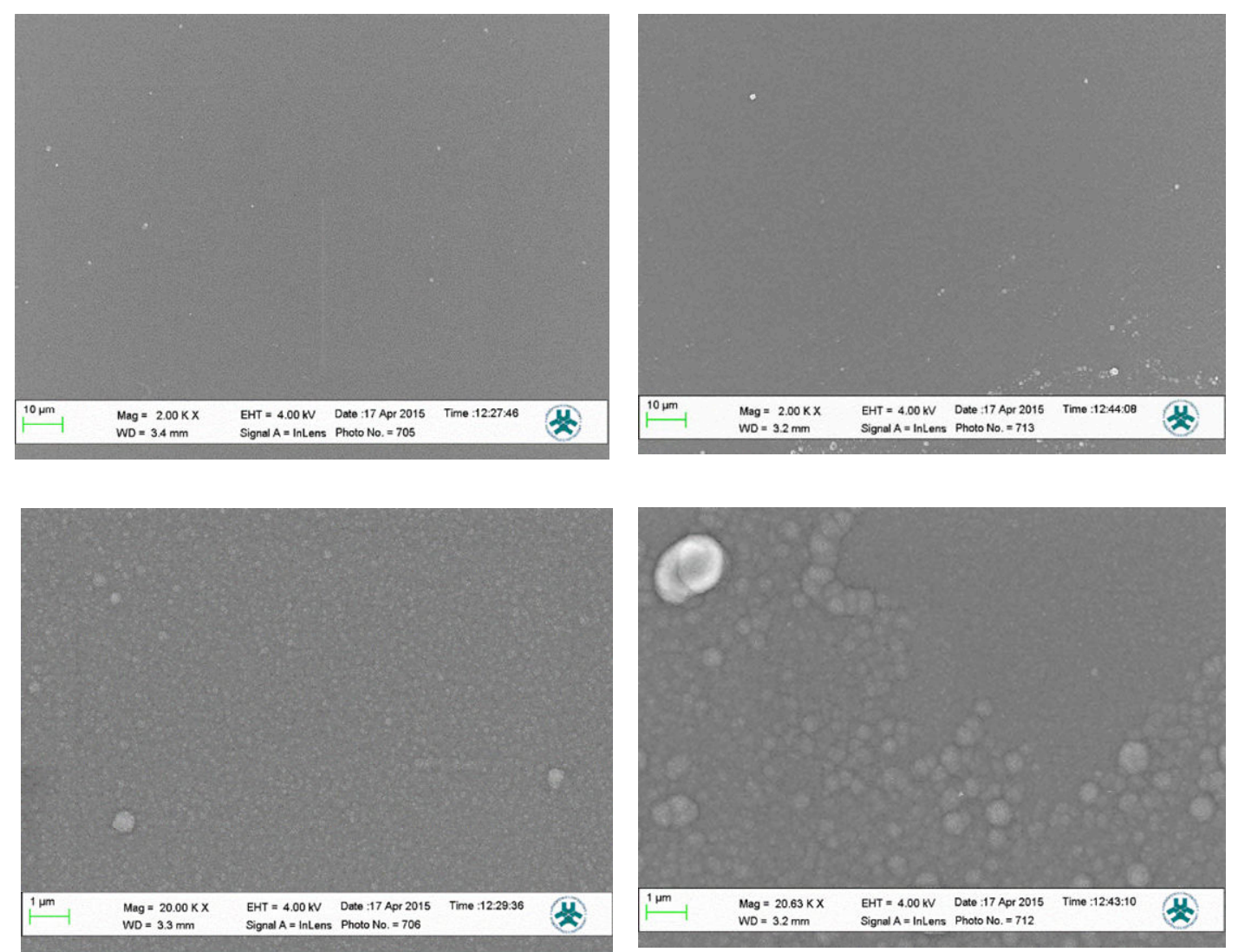

Reduced

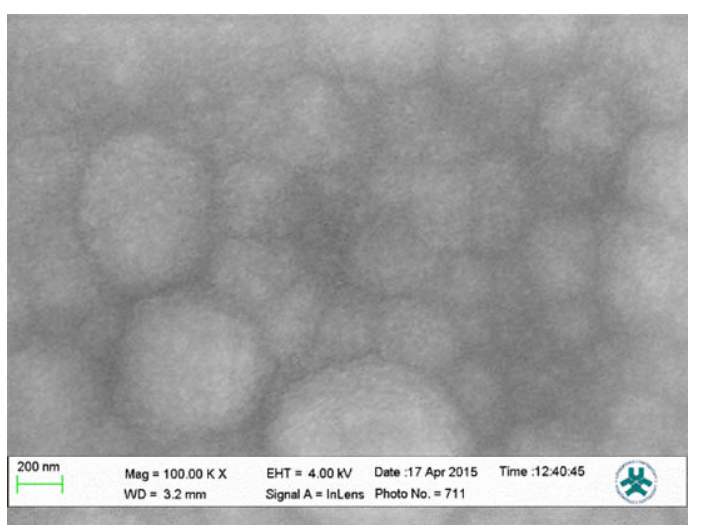

\section{Oxidized}
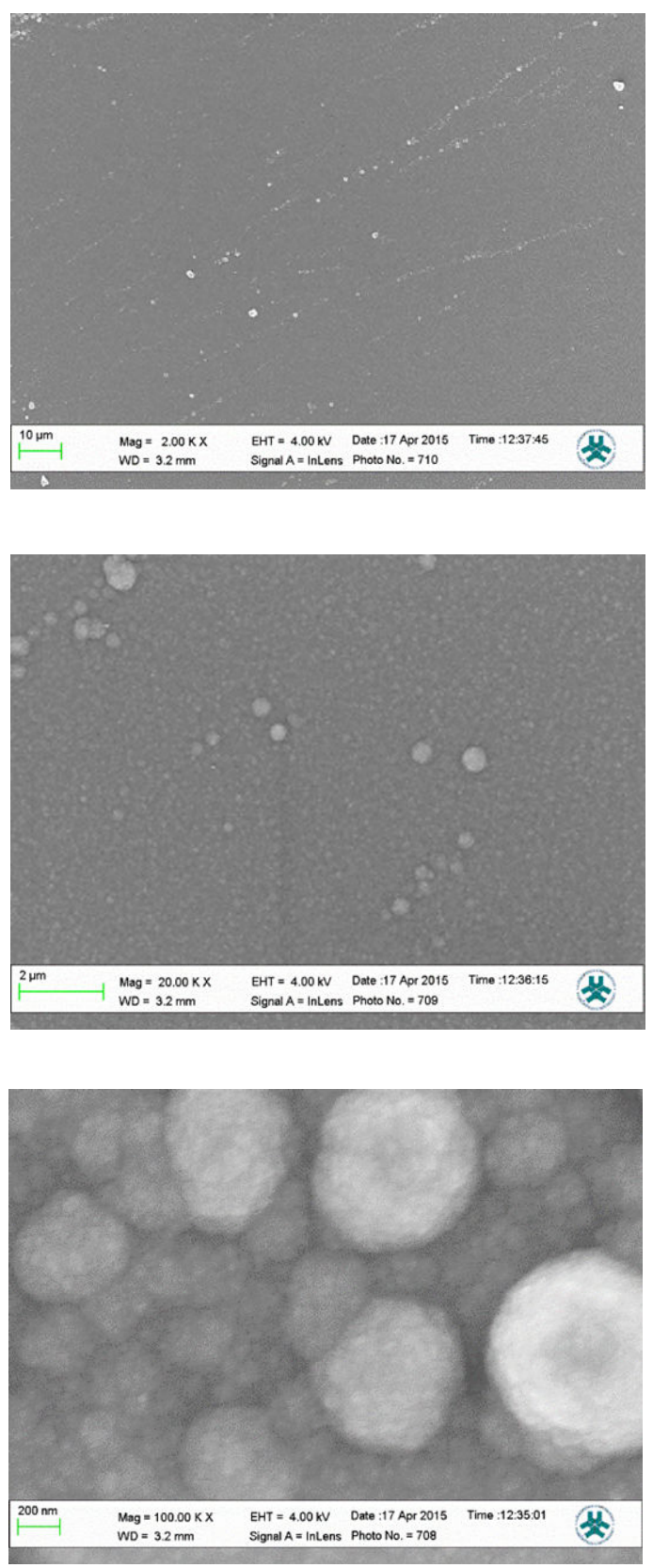
Fabricated Reduced
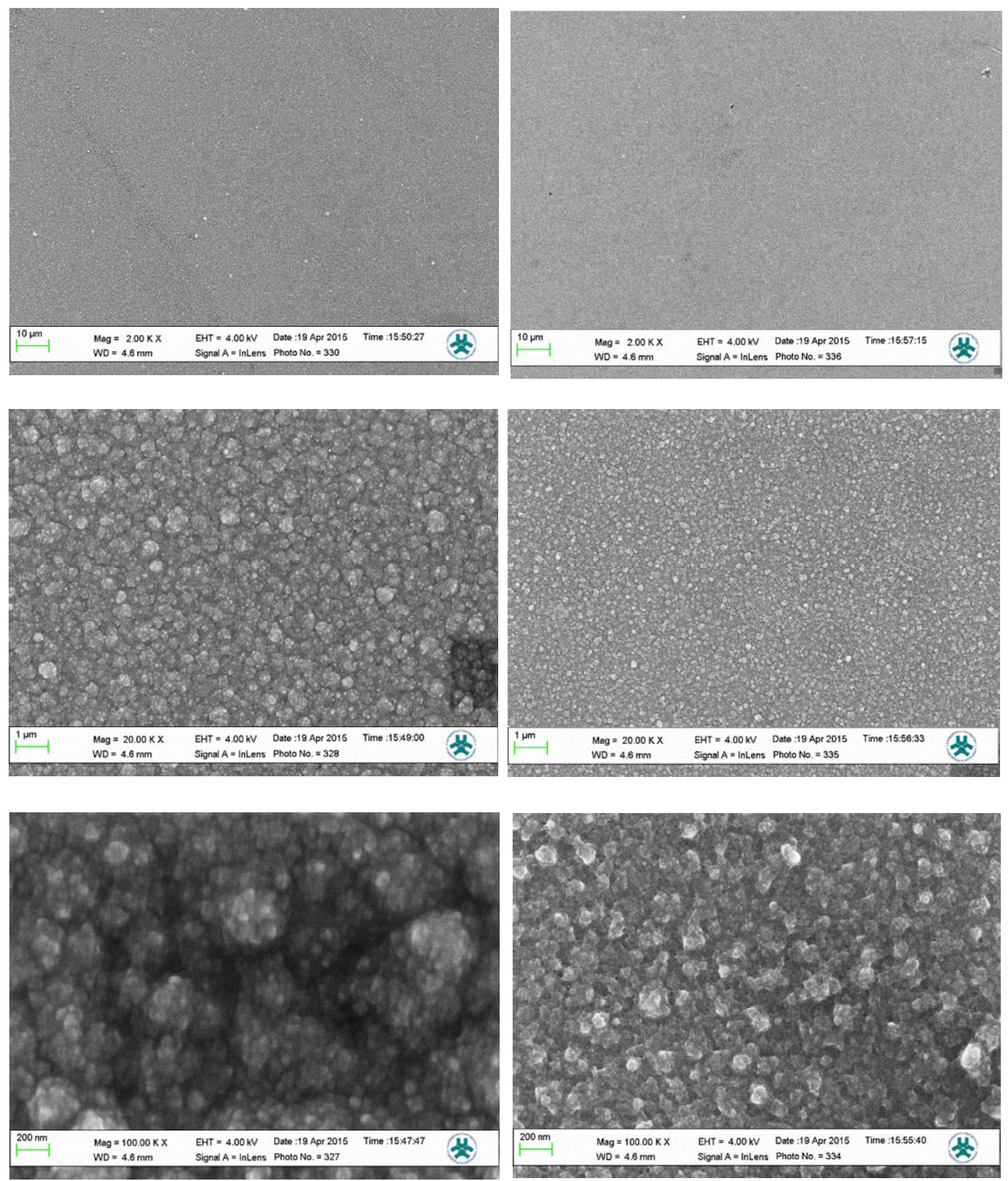

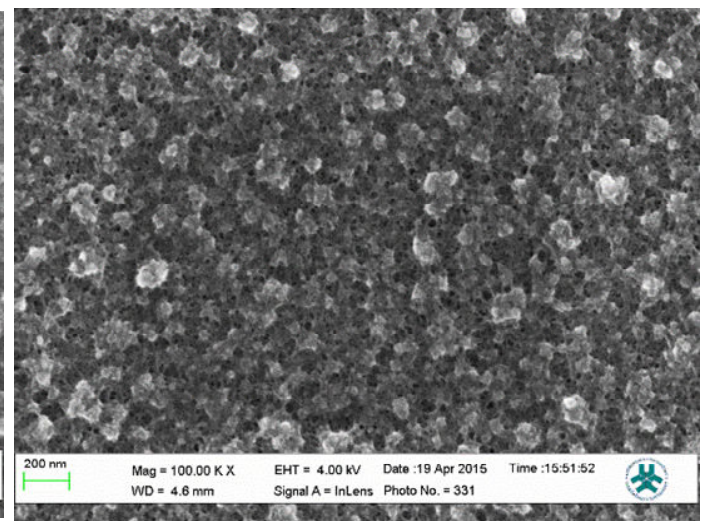


Fabricated
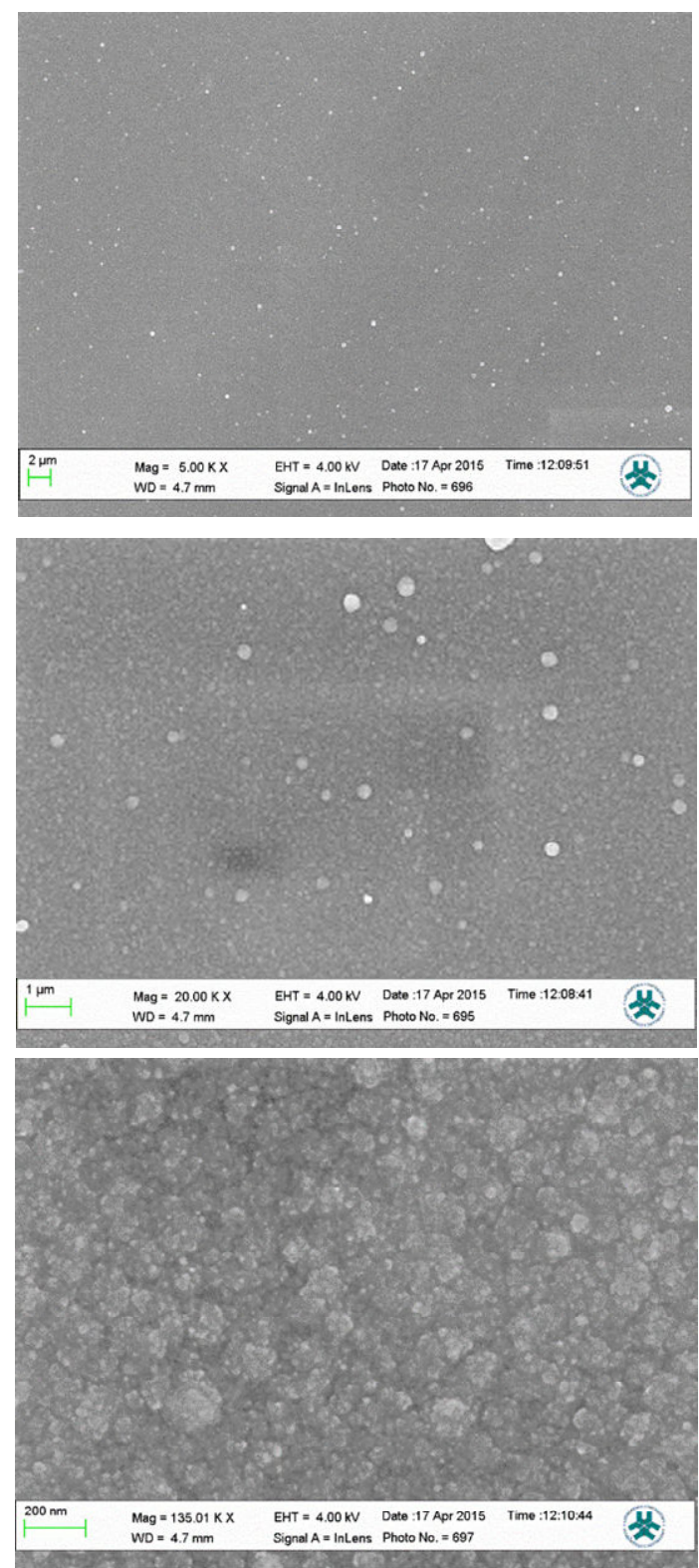

$$
\text { }
$$

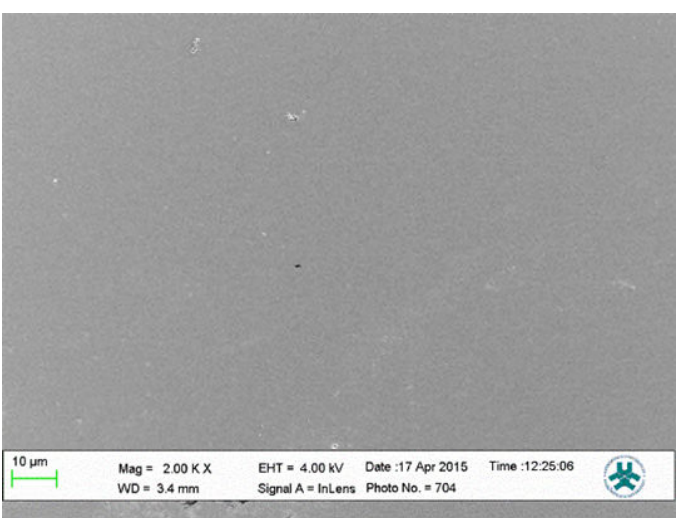

PPy-Cl

Reduced
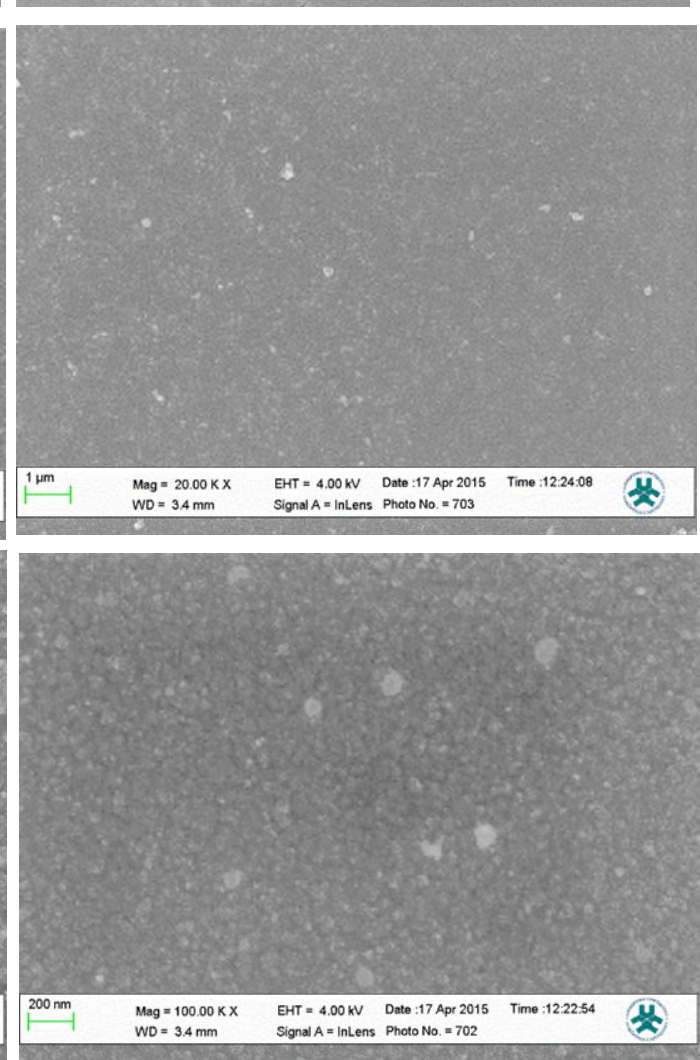

\section{Oxidized}
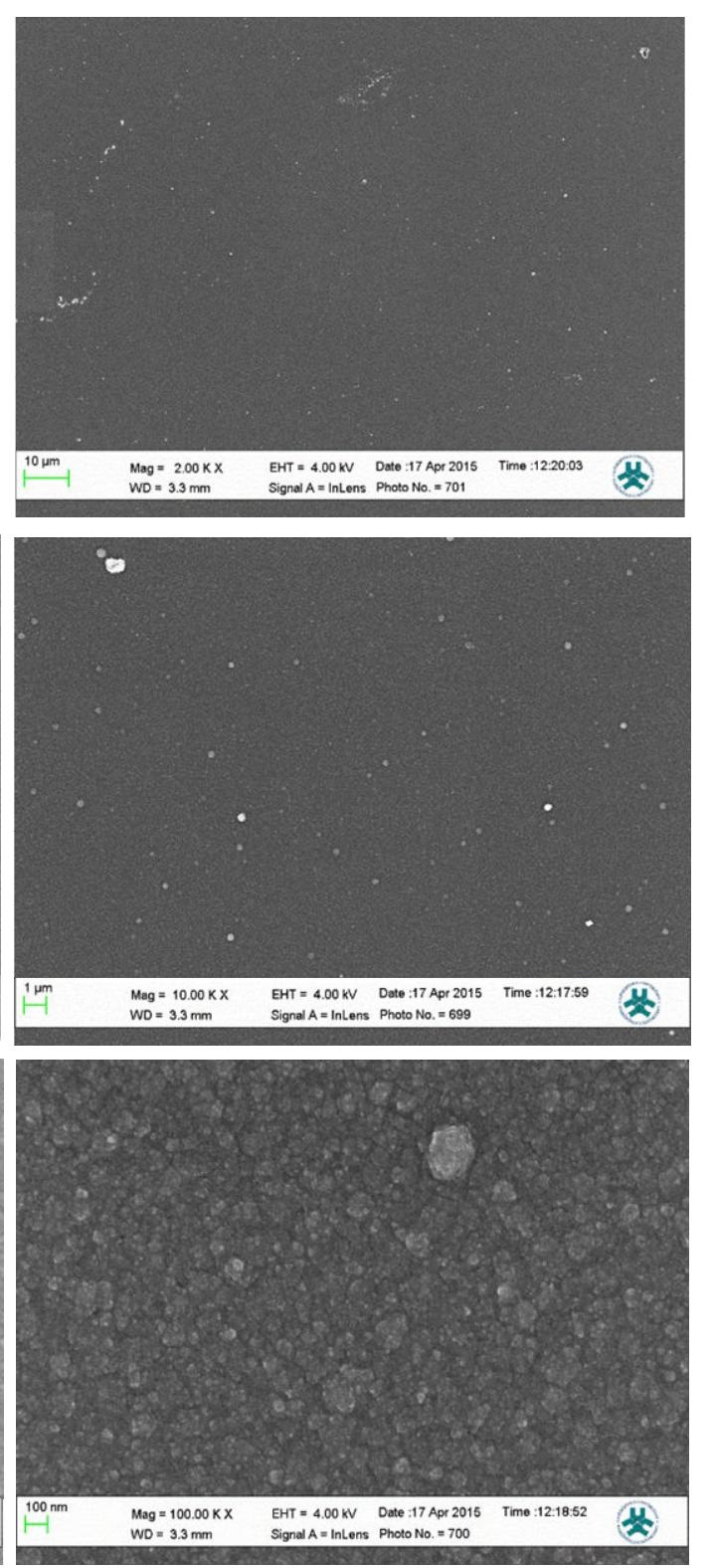
Fig. S3B. SEM Images of polypyrrole doped with Cl, DBS, PSS and ToS in the as fabricated, reduced and oxidized states at different magnifications.

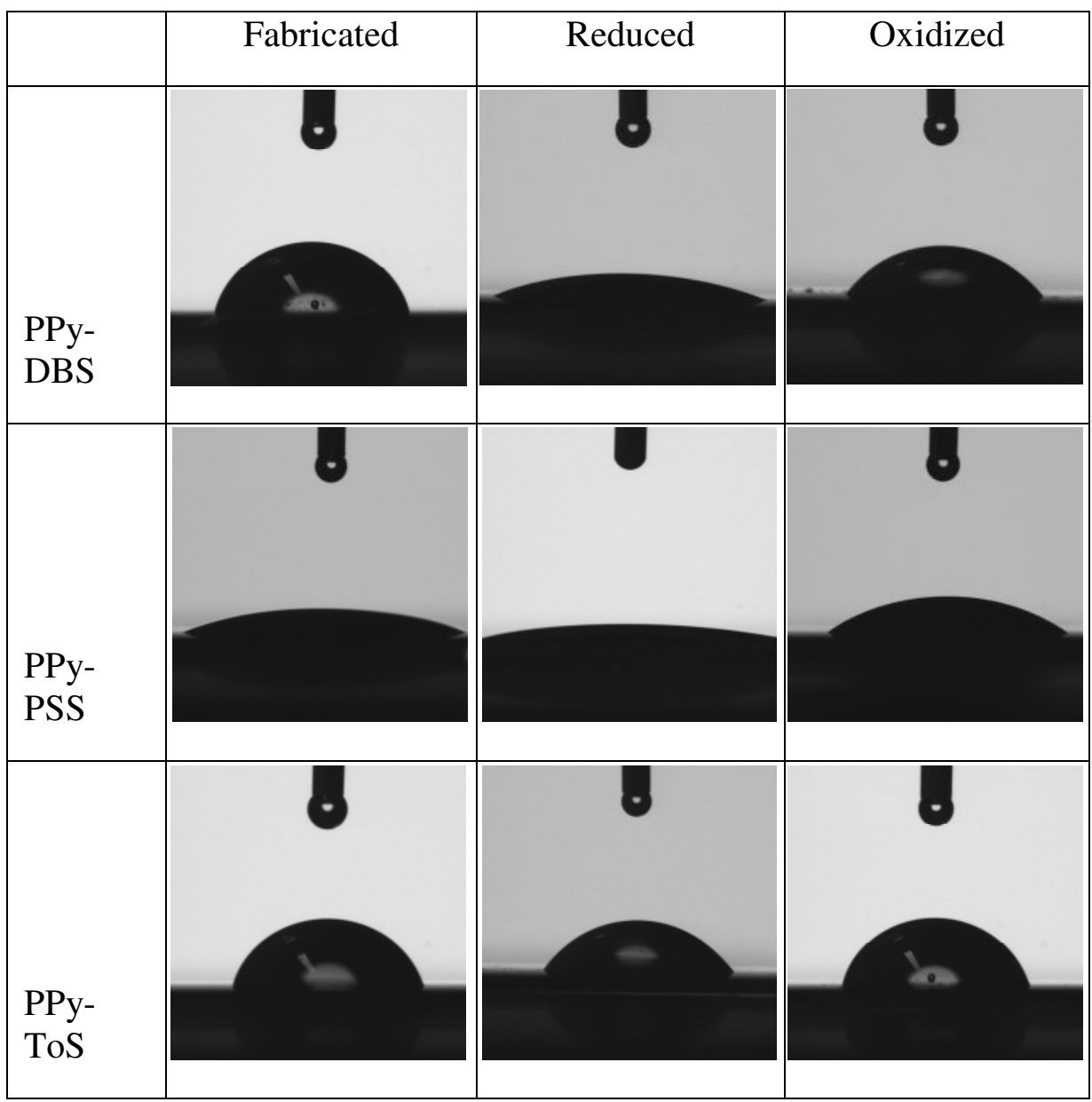




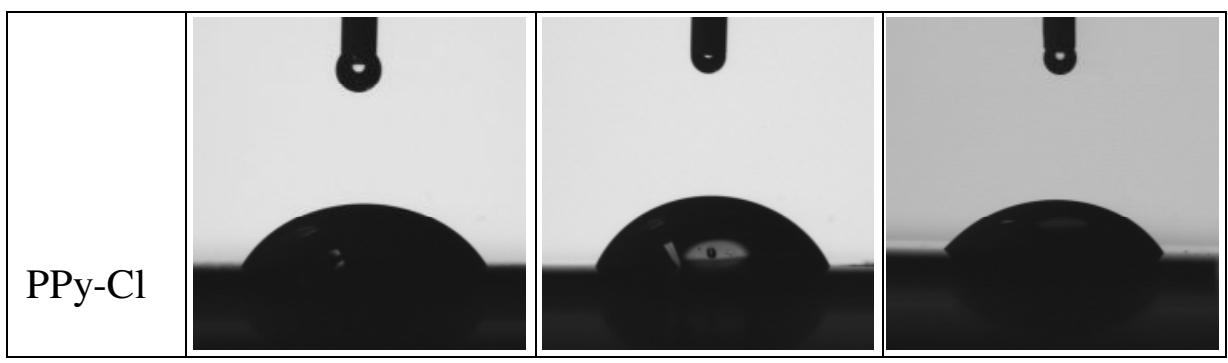

Fig. S4. Water contact angle Images of polypyrrole doped with $\mathrm{Cl}, \mathrm{DBS}, \mathrm{PSS}$ and ToS in the as fabricated, reduced and oxidized.

different bacterial strains. Also, we have shown that by using different dopants and changing the electropolymerisation conditions, we can easily fabricate a range of PPy films with different surface properties. Future work will include expanding the size and diversity of the array including dynamic addressing (i.e. real-time modulation of the surface properties), microfabrication and miniaturisation, the use of more sophisticated multivariate analysis and pattern recognition software, and simpler non-optical detection methods such as impedance analysis. Thereafter, we will investigate discriminating further related bacterial strains and their discrimination in mixed cultures. We envisage that this approach could provide a valuable in-line or on-line method for monitoring fluctuations in microbial populations in real time. 
Figure 1. Physical properties, hydrophobicity (a) roughness (b) and thickness (c), of asfabricated, oxidised and reduced polypyrrole doped with different counter ion. All polymers were fabricated under the same electrochemical conditions using $0.1 \mathrm{M}$ pyrrole and $0.1 \mathrm{M}$ dopant in aqueous solution $(\mathrm{E}=650 \mathrm{mV}$ and $\mathrm{Q}=100 \mathrm{mC})$. Oxidation and reduction of each polymer was performed in its dopant $(0.1 \mathrm{M})$ aqueous solution using $+0.3 \mathrm{v}$ and $-0.9 \mathrm{v}$ for 300 s to oxidise or reduce the fabricated polymer, respectively. The data are averages of three independent experiments and error bar indicates standard deviation.

Figure 2a. Fluorescent microscope images of A.faecalis, S.marcescens, P.fluorescens S.epidermidis and D.proteolyticus adhered on different doped polypyrrole surfaces. All polymers were fabricated under the same conditions other than varying the counter ion, using $0.1 \mathrm{M}$ pyrrole and 0.1 $\mathrm{M}$ dopant in aqueous solution $(\mathrm{E}=650 \mathrm{mV}$ and $\mathrm{Q}=100 \mathrm{mC})$. Polymer samples were seeded with $7.5 \mathrm{ml}$ of $10^{8} \mathrm{cfu} / \mathrm{ml}$ bacterial suspension for 60 minutes in $37^{\circ} \mathrm{C}$ and $70 \mathrm{rpm}$.

Figure 2b. Quantitative representation of the effects of different doping of polypyrrole on bacterial adhesion to its surface. Four doped polypyrrole films were exposed by different bacterial suspension $\left(7.5 \mathrm{ml}\right.$ of $\left.10^{8} \mathrm{cfu} / \mathrm{ml}, 60 \mathrm{~min}\right)$. The numbers of bacteria were determined by fluorescent dye staining and imaging. The data are averages of three independent experiments and error bars indicate standard deviations.

Figure 3. An example of tuning of the PPy surfaces by altering the redox state to add an additional level of bacterial discrimination. A.faecalis and S.marcescens showed the same adhesion tendency to the both fabricated PSS and ToS doped polypyrrole, but different adhesion 
tendencies where evident when the polymers where reduced, or oxidised, respectively. The data are averages of three independent experiments and error bars indicate standard deviations.

Figure 4. The pattern adhesion of different bacteria on the full set of polypyrrole surfaces, both different dopants and redox states. The data are averages of three independent experiments and error bars indicate standard deviations.

Figure 5 (a) PCA score plot and (b) loading plot of the adhesion pattern of bacteria. The plot is based on the data in figure 4.

\section{Corresponding Author}

Edwin Jager, edwin.jager@liu.se

Biosensors and Bioelectronics Centre, IFM, Linköping University, 581 83, Linköping, Sweden

\section{ACKNOWLEDGMENT}

Mohsen Golabi acknowledges the Iranian Ministry of Science, Research and Technology for supporting his Ph.D. Anthony P F Turner and Edwin Jager thank Linköping University for financial support. The authors would also like to acknowledge Dr. Valerio Beni and Dr. Hirak K. Patra for valuable discussions and help with the experiments and Prof. Fredrik Winquist for help with the PCA analysis.

\section{REFERENCES}

[1] P.B. Lillehoj, C.W. Kaplan, J. He, W. Shi, C.M. Ho, Rapid, Electrical Impedance Detection of Bacterial Pathogens Using Immobilized Antimicrobial Peptides, Journal of Laboratory Automation, 19(2014) 42-9.

[2] G.A. Zelada-Guillen, J. Riu, A. Duzgun, F.X. Rius, Immediate Detection of Living Bacteria at Ultralow Concentrations Using a Carbon Nanotube Based Potentiometric Aptasensor, Angewandte Chemie-International Edition, 48(2009) 7334-7. 
[3] A.K. Bhunia, Biosensors and Bio-Based Methods for the Separation and Detection of Foodborne Pathogens, in: L.T. Steve (Ed.) Advances in Food and Nutrition Research, Academic Press2008, pp. 1-44.

[4] A. Van Belkum, G. Durand, M. Peyret, S. Chatellier, G. Zambardi, J. Schrenzel, et al., Rapid clinical bacteriology and its future impact, Annals of Laboratory Medicine, 33(2013) 14-27.

[5] W.J. Sung, Y.H. Bae, A glucose oxidase electrode based on polypyrrole with polyanion/PEG/enzyme conjugate dopant, Biosensors and Bioelectronics, 18(2003) 1231-9.

[6] G.G. Wallace, L.A.P. Kane-Maguire, Manipulating and monitoring biomolecular interactions with conducting electroactive polymers, Advanced Materials, 14(2002) 953-60.

[7] R.R. Dutta, P. Puzari, Amperometric biosensing of organophosphate and organocarbamate pesticides utilizing polypyrrole entrapped acetylcholinesterase electrode, Biosensors and Bioelectronics, 52(2014) 166-72.

[8] X. Cui, D.C. Martin, Electrochemical deposition and characterization of poly(3,4ethylenedioxythiophene) on neural microelectrode arrays, Sensors and Actuators B: Chemical, 89(2003) 92-102.

[9] T. Nyberg, A. Shimada, K. Torimitsu, Ion conducting polymer microelectrodes for interfacing with neural networks, Journal of Neuroscience Methods, 160(2007) 16-25. [10] J.Y. Wong, R. Langer, D.E. Ingber, Electrically conducting polymers can nonivasively control the shape and growth of mammalian-cells, , Proceedings of the National Academy of Sciences of the United States of America, 91(1994) 3201-4.

[11] C.E. Schmidt, V.R. Shastri, J.P. Vacanti, R. Langer, Stimulation of neurite outgrowth using an electrically conducting polymer, Proceedings of the National Academy of Sciences of the United States of America, 94(1997) 8948-53.

[12] K. Svennersten, M.H. Bolin, E.W.H. Jager, M. Berggren, A. Richter-Dahlfors, Electrochemical modulation of epithelia formation using conducting polymers, Biomaterials, 30(2009) 6257-64.

[13] A. Herland, K.M. Persson, V. Lundin, M. Fahlman, M. Berggren, E.W.H. Jager, et al., Electrochemical Control of Growth Factor Presentation To Steer Neural Stem Cell Differentiation, Angewandte Chemie-International Edition, 50(2011) 12529-33.

[14] B. Zinger, L.L. Miller, Timed release of chemicals from polypyrrole films, J Am Chem Soc, 106(1984) 6861-3.

[15] R. Wadhwa, C.F. Lagenaur, X.T. Cui, Electrochemically controlled release of dexamethasone from conducting polymer polypyrrole coated electrode, Journal of Controlled Release, 110(2006) 531-41.

[16] K. Svennersten, M. Berggren, A. Richter-Dahlfors, E.W.H. Jager, Mechanical stimulation of epithelial cells using polypyrrole microactuators, Lab on a Chip, 11(2011) 3287-93.

[17] A. Gelmi, M.J. Higgins, G.G. Wallace, Physical surface and electromechanical properties of doped polypyrrole biomaterials, Biomaterials, 31(2010) 1974-83.

[18] A. Gelmi, M.K. Ljunggren, M. Rafat, E.W. Jager, Influence of Conductive Polymer Doping on the Viability of Cardiac Progenitor Cells, Journal of Materials Chemistry B, (2014).

[19] V. Lundin, A. Herland, M. Berggren, E.W.H. Jager, A.I. Teixeira, Control of neural stem cell survival by electroactive polymer substrates, Plos One, 6(2011).

[20] D.H. Kim, S.M. Richardson-Burns, J.L. Hendricks, C. Sequera, D.C. Martin, Effect of immobilized nerve growth factor on conductive polymers: Electrical properties and cellular response, Advanced Functional Materials, 17(2007) 79-86. 
[21] J.M. Fonner, L. Forciniti, H. Nguyen, J.D. Byrne, Y.F. Kou, J. Syeda-Nawaz, et al., Biocompatibility implications of polypyrrole synthesis techniques, Biomedical Materials, 3(2008).

[22] L.B. Xu, W. Chen, A. Mulchandani, Y.S. Yan, Reversible conversion of conducting polymer films from superhydrophobic to superhydrophilic, Angewandte Chemie-International Edition, 44(2005) 6009-12.

[23] M. Mindroiu, C. Ungureanu, R. Ion, C. Pirvu, The effect of deposition electrolyte on polypyrrole surface interaction with biological environment, Applied Surface Science, 276(2013) 401-10.

[24] K.J. Gilmore, M. Kita, Y. Han, A. Gelmi, M.J. Higgins, S.E. Moulton, et al., Skeletal muscle cell proliferation and differentiation on polypyrrole substrates doped with extracellular matrix components, Biomaterials, 30(2009) 5292-304.

[25] U. Dharmasiri, M.A. Witek, A.A. Adams, J.K. Osiri, M.L. Hupert, T.S. Bianchi, et al., Enrichment and Detection of Escherichia coli O157:H7 from Water Samples Using an Antibody Modified Microfluidic Chip, Analytical Chemistry, 82(2010) 2844-9.

[26] S. Perni, P. Prokopovich, Micropatterning with conical features can control bacterial adhesion on silicone, Soft Matter, 9(2013) 1844-51.

[27] J.W. Costerton, Z. Lewandowski, D.E. Caldwell, D.R. Korber, H.M. Lappinscott, MICROBIAL BIOFILMS, Annual Review of Microbiology, 49(1995) 711-45.

[28] S. Bayoudh, A. Othmane, F. Bettaieb, A. Bakhrouf, H.B. Ouada, L. Ponsonnet, Quantification of the adhesion free energy between bacteria and hydrophobic and hydrophilic substrata, Materials Science and Engineering: C, 26(2006) 300-5.

[29] W. Krzyściak, A. Jurczak, D. Kościelniak, B. Bystrowska, A. Skalniak, The virulence of Streptococcus mutans and the ability to form biofilms, European Journal of Clinical Microbiology \& Infectious Diseases, 33(2014) 499-515.

[30] L.C. Hsu, J. Fang, D.A. Borca-Tasciuc, R.W. Worobo, C.I. Moraru, Effect of micro- and nanoscale topography on the adhesion of bacterial cells to solid surfaces, Applied and Environmental Microbiology, 79(2013) 2703-12.

[31] M.R. Park, M.K. Banks, B. Applegate, T.J. Webster, Influence of nanophase titania topography on bacterial attachment and metabolism, International Journal of Nanomedicine, 3(2008) 497-504.

[32] D. Dutta, N. Cole, M. Willcox, Factors influencing bacterial adhesion to contact lenses, Molecular Vision, 18(2012) 14-21.

[33] K. Hori, S. Matsumoto, Bacterial adhesion: From mechanism to control, Biochemical Engineering Journal, 48(2010) 424-34.

[34] J. Palmer, S. Flint, J. Brooks, Bacterial cell attachment, the beginning of a biofilm, Journal of Industrial Microbiology \& Biotechnology, 34(2007) 577-88.

[35] S. Perni, T.G. Aldsworth, S.J. Jordan, I. Fernandes, M. Barbosa, M. Sol, et al., The resistance to detachment of dairy strains of Listeria monocytogenes from stainless steel by shear stress is related to the fluid dynamic characteristics of the location of isolation, International Journal of Food Microbiology, 116(2007) 384-90.

[36] J. Szlavik, D.S. Paiva, N. Mork, F. van den Berg, J. Verran, K. Whitehead, et al., Initial adhesion of Listeria monocytogenes to solid surfaces under liquid flow, International Journal of Food Microbiology, 152(2012) 181-8. 
[37] J. Mukherjee, E. Karunakaran, C.A. Biggs, Using a multi-faceted approach to determine the changes in bacterial cell surface properties influenced by a biofilm lifestyle, Biofouling, 28(2012) 1-14.

[38] H. Gu, D. Ren, Materials and surface engineering to control bacterial adhesion and biofilm formation: A review of recent advances, Frontiers of Chemical Science and Engineering, 8(2014) 20-33.

[39] O. Habimana, A.J.C. Semião, E. Casey, The role of cell-surface interactions in bacterial initial adhesion and consequent biofilm formation on nanofiltration/reverse osmosis membranes, Journal of Membrane Science, 454(2014) 82-96.

[40] C.M. McEntegart, W.R. Penrose, S. Strathmann, J.R. Stetter, Detection and discrimination of coliform bacteria with gas sensor arrays, Sensors and Actuators, B: Chemical, 70(2000) 1706.

[41] V. Sberveglieri, E.N. Carmona, E. Comini, A. Ponzoni, D. Zappa, O. Pirrotta, et al., A novel electronic nose as adaptable device to judge microbiological quality and safety in foodstuff, BioMed Research International, 2014(2014).

[42] T.R. Garrett, M. Bhakoo, Z. Zhang, Bacterial adhesion and biofilms on surfaces, Progress in Natural Science, 18(2008) 1049-56.

[43] A. Pavlou, A.P.F. Turner, N. Magan, Recognition of anaerobic bacterial isolates in vitro using electronic nose technology, Letters in Applied Microbiology, 35(2002) 366-9.

[44] S. Wold, K. Esbensen, P. Geladi, Principal component analysis, Chemometrics and Intelligent Laboratory Systems, 2(1987) 37-52.

[45] M. Geoghegan, J.S. Andrews, C.A. Biggs, K.E. Eboigbodin, D.R. Elliott, S. Rolfe, et al., The polymer physics and chemistry of microbial cell attachment and adhesion, Faraday Discussions, 139(2008) 85-103.

[46] A. Almaguer-Flores, L.A. Ximenez-Fyvie, S.E. Rodil, Oral Bacterial Adhesion on Amorphous Carbon and Titanium Films: Effect of Surface Roughness and Culture Media, Journal of Biomedical Materials Research Part B-Applied Biomaterials, 92B(2010) 196-204. [47] R.M. Donlan, Biofilms: Microbial life on surfaces, Emerging Infectious Diseases, 8(2002) 881-90.

[48] I. Banerjee, R.C. Pangule, R.S. Kane, Antifouling Coatings: Recent Developments in the Design of Surfaces That Prevent Fouling by Proteins, Bacteria, and Marine Organisms, Advanced Materials, 23(2011) 690-718.

[49] H.H. Tuson, D.B. Weibel, Bacteria-surface interactions, Soft Matter, 9(2013) 4368-80.

[50] Y.H. An, R.J. Friedman, Concise review of mechanisms of bacterial adhesion to biomaterial surfaces, Journal of Biomedical Materials Research, 43(1998) 338-48.

[51] J.A. Lichter, K.J. Van Vliet, M.F. Rubner, Design of Antibacterial Surfaces and Interfaces: Polyelectrolyte Multilayers as a Multifunctional Platform, Macromolecules, 42(2009) 8573-86. [52] X.X. Zhang, L. Wang, E. Levanen, Superhydrophobic surfaces for the reduction of bacterial adhesion, Rsc Advances, 3(2013) 12003-20.

[53] Y. Wibisono, W. Yandi, M. Golabi, R. Nugraha, Emile R. Cornelissen, A.J.B. Kemperman, et al., Hydrogel-coated feed spacers in two-phase flow cleaning in spiral wound membrane elements: A novel platform for eco-friendly biofouling mitigation, Water Research, 71(2015) 171-86.

[54] A.A. Myint, W. Lee, S. Mun, C.H. Ahn, S. Lee, J. Yoon, Influence of membrane surface properties on the behavior of initial bacterial adhesion and biofilm development onto nanofiltration membranes, Biofouling, 26(2010) 313-21. 
[55] H.C. van der Mei, R. Bos, H.J. Busscher, A reference guide to microbial cell surface hydrophobicity based on contact angles, Colloids and Surfaces B: Biointerfaces, 11(1998) 21321.

[56] C. Desrousseaux, V. Sautou, S. Descamps, O. Traore, Modification of the surfaces of medical devices to prevent microbial adhesion and biofilm formation, Journal of Hospital Infection, 85(2013) 87-93.

[57] K.A. Whitehead, J. Verran, The effect of surface topography on the retention of microorganisms, Food and Bioproducts Processing, 84(2006) 253-9.

[58] C. Faille, J.M. Membre, J.P. Tissier, M.N. Bellon-Fontaine, B. Carpentier, M.A. Laroche, et al., Influence of physicochemical properties on the hygienic status of stainless steel with various finishes, Biofouling, 15(2000) 261-74.

[59] Y.T. Tsai, C.H. Choi, N. Gao, E.H. Yang, Tunable wetting mechanism of polypyrrole surfaces and low-voltage droplet manipulation via redox, Langmuir, 27(2011) 4249-56. [60] M. Dobbelin, R. Tena-Zaera, R. Marcilla, J. Iturri, S. Moya, J.A. Pomposo, et al., Multiresponsive PEDOT-Ionic Liquid Materials for the Design of Surfaces with Switchable Wettability, Advanced Functional Materials, 19(2009) 3326-33.

[61] I. Yoda, H. Koseki, M. Tomita, T. Shida, H. Horiuchi, H. Sakoda, et al., Effect of surface roughness of biomaterials on Staphylococcus epidermidis adhesion, BMC Microbiology, 14(2014).

[62] A.G. Gehring, S.I. Tu, High-Throughput Biosensors for Multiplexed Food-Borne Pathogen Detection, in: R.G. Cooks, E.S. Yeung (Eds.), Annual Review of Analytical Chemistry, Vol 42011, pp. 151-72.

[63] R.J. Crawford, H.K. Webb, V.K. Truong, J. Hasan, E.P. Ivanova, Surface topographical factors influencing bacterial attachment, Advances in Colloid and Interface Science, 179(2012) $142-9$.

[64] A.Y. Rad, H. Ayhan, Ü. Kisa, E. Pişkin, Adhesion of different bacterial strains to lowtemperature plasma treated biomedical PVC catheter surfaces, Journal of Biomaterials Science, Polymer Edition, 9(1998) 915-29.

[65] K. Triandafillu, D.J. Balazs, B.O. Aronsson, P. Descouts, P. Tu Quoc, C. Van Delden, et al., Adhesion of Pseudomonas aeruginosa strains to untreated and oxygen-plasma treated poly(vinyl chloride) (PVC) from endotracheal intubation devices, Biomaterials, 24(2003) 1507-18.

[66] J.W. Gardner, M. Craven, C. Dow, E.L. Hines, The prediction of bacteria type and culture growth phase by an electronic nose with a multi-layer perceptron network, Measurement Science and Technology, 9(1998) 120-7.

[67] R. Dutta, A. Das, N.G. Stocks, D. Morgan, Stochastic resonance-based electronic nose: A novel way to classify bacteria, Sensors and Actuators, B: Chemical, 115(2006) 17-27.

[68] G.C. Green, A.D.C. Chan, M. Lin, Robust identification of bacteria based on repeated odor measurements from individual bacteria colonies, Sensors and Actuators, B: Chemical, 190(2014) $16-24$. 
2015-09-08

Tunable conjugated polymers for bacterial differentiation

\author{
Golabi, Mohsen
}

Elsevier

Golabi M, Turner A, Jager E. (2016) Tunable conjugated polymers for bacterial differentiation.

Sensors and Actuators B: Chemical, Volume 222, January 2016, pp. 839-848

https://doi.org/10.1016/j.snb.2015.09.033

Downloaded from Cranfield Library Services E-Repository 